\title{
Design of Remote Incoming Supply Disconnection System using Radio Frequency (RF)
}

\author{
Samshul Munir Muhamad, Mohammad Nawawi Seroji, and Mohd Saleh Shamlani
}

\begin{abstract}
When dealing with unpaid bills, TNB usually ends up to cut OFF the electricity supply to the premise by removing the fuse from the energy meter box. However, this is difficult to be carried out since the meter is sometime inaccessible due to its location, being locked as well as guarded by dogs. This paper proposes a remote system to disconnect the electrical supply via Radio Frequency wave. In this system an additional disconnection device is required to be installed together with the consumer energy meter unit. The transmitter and receiver are equipped with RF module which facilitates one directional communication to perform the disconnection task. The system is also capable to reconnect the supply. It is hoped that the system could reduce the non-payment issues.
\end{abstract}

Index Terms - remote disconnection, electricity theft, unpaid bill, radio frequency

\section{INTRODUCTION}

$\mathrm{N}$ OWADAYS, electricity has become a basic need for humans. The consumption of electricity has increased a lot compared to the past years[1]. In general, generation, transmission, and distribution of electricity involve many operating losses. Losses from generation can be technically defined, but transmission and distribution losses cannot be precisely quantified from the sending end information [2]. The losses in electrical system can be categorised into two types: Technical losses and Non-Technical Losses.

Technical losses include electrical system losses which are caused by network impedance, current flows and auxiliary supplies. Non-technical losses include illegal tapping of electricity from the feeder, bypassing the energy meter, tampering with the energy meter, billing irregularities and unpaid bills. In 2004, Tenaga Nasional Berhad (TNB) Sdn. Bhd., the sole electricity provider in Malaysia recorded revenue losses as high as USD 229 million a year as a result of electricity theft, billing errors, faulty metering and unpaid bills[4].

This manuscript is submitted on 26 September 2019 and accepted on 9 September 2020. Samshul Munir Muhamad and Mohammad Nawawi Seroji are fromFaculty of Electrical Engineering, Universiti Teknologi MARA, 40450 Shah Alam, Selangor (e-mail: samshulmunir@yahoo.com).

Mohd Saleh Shamlani is Executive Chairman of SHR Group. The company focuses in Electrical Engineering - power such as on concracting, manufacturing and engineering services (e-mail: mshamlani@yahoo.com.sg).

1985-5389/C 2021 The Authors. Published by UiTM Press. This is an open access article under the CC BY-NC-ND license (http://creativecommons.org/ licenses/by-nc-nd/4.0/).
In Malaysia, energy meter is installed on the consumer's premises outside the premises and the consumption information or electricity usage is collected by meter readers on monthly basis by visiting the premises. As a normal business practice, TNB issues disconnection notices to all outstanding accounts once the payment becomes due one month after issuance of the bills. If the payment is not received within the stipulated time, TNB will instruct staffs to visit physically to the premise and remove the fuse box from energy meter to disconnect the electricity. However, the problems of removing the fuse by TNB staffs in the previous were identified as unable to get access to the energy meter since it is unreachable due to its location, locked gates, locked meter box and guarded by fierce dogs. Hence, this research is aimed to remote supply control device for single phase meter to cut off incoming supply without taking out the fuse from the box. To ensure minimizing the mistake cut off main power supply, the device can be remotely activated for a distance 10 meter.

This disconnection system for the energy meter will assist the disconnection staffs or contractor employed by TNB to cut off the electrical supply by using Radio Frequency (RF) $433 \mathrm{Mhz}$ remote control device. The disconnection device is capable to remote obstruction conditions.

\section{PROPOSED SYSTEM DESIGN}

Fig. 1 illustrates the basic system design. The disconnection device will be connected to main supply from the service provider. before the energy meter.

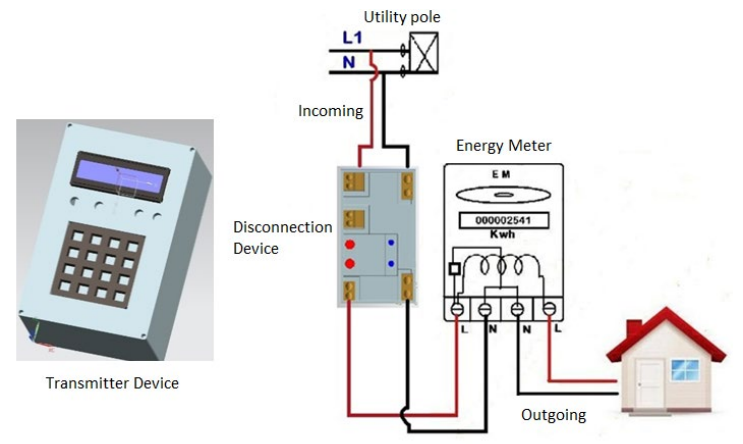

Fig. 1. Basic System Design 


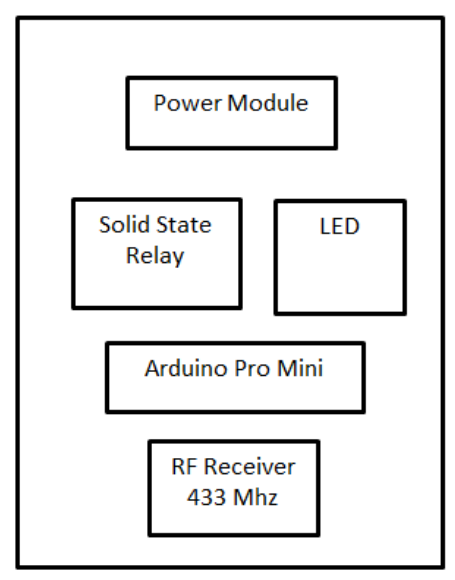

Disconnection Device

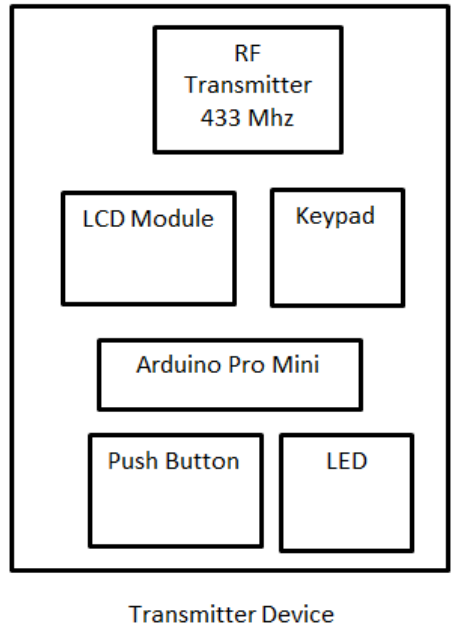

Fig. 2. System Architecture of Transmitter Device and Disconnection Device

Fig. 2 shows the system architecture for the disconnection system which consists of transmitter device and disconnection device. The device receives supply from the live and neutral wire from a supply that is connected to the power module. It converts $230 \mathrm{~V}$ alternating current (AC) to $5 \mathrm{~V}$ direct current (DC) using rectifier to provide supply to the Arduino Pro Mini. The live wire is also connected to load through solid state module inside the device. When the disconnection device receives the signal, it is able to either cut OFF or reconnect the load. The transmitter device that sends the signal mainly consists of RF transmitter module, Arduino Pro mini, push button, keypad, and LCD module.

\section{HARDWARE DESIGN}

This project has two controllers being the switch disconnection device and transmitter device. In designing the disconnection device, solid state switch is used to cut OFF the load. The function of microcontroller used in the disconnection device is to control the switching of solid state relay to load. The communication between Transmitter device and disconnection device is used standard Radio Frequency $433 \mathrm{MHz}$ Module. For safety purpose, the design of the casing should have a protection and is not exposed the circuit to the user.

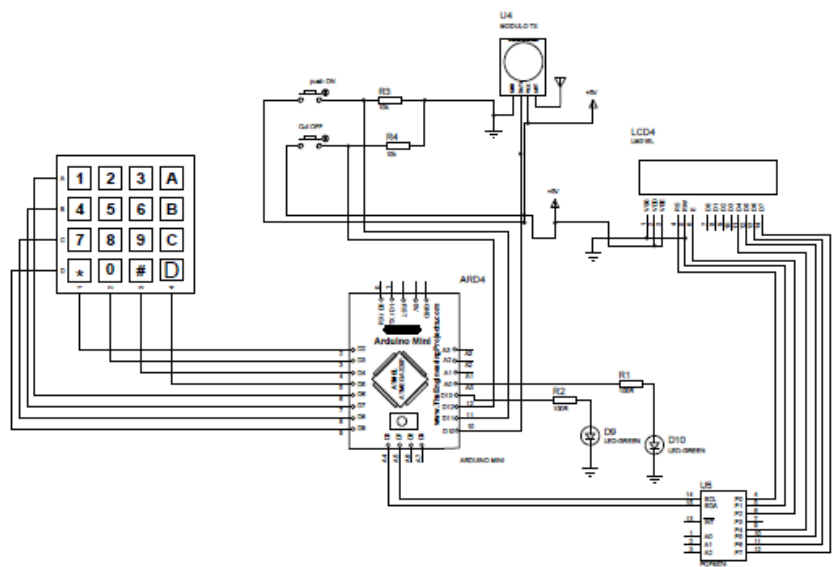

Fig. 3. Transmitter circuit

Fig. 3 shows the transmitter circuit device including Arduino Pro Mini, RF Transmitter module, keypad, push button, LEDs and LCD module.

Fig. 4 shows disconnection circuit which includes power module, Arduino Pro Mini and RF receiver. Solid State Relay used as switching to control ON or OFF the load. There are 4 types of solid-state relays namely zero-switching relay, instant ON relay, peak switching relay and analogue switching relay. Zero crossing solid state was used to minimize the surge current through the load during the first conduction cycle and reduce the level of conducted emission placed on the AC mains. The connector pins are used to connect the disconnection device to the live and neutral of the main supply.

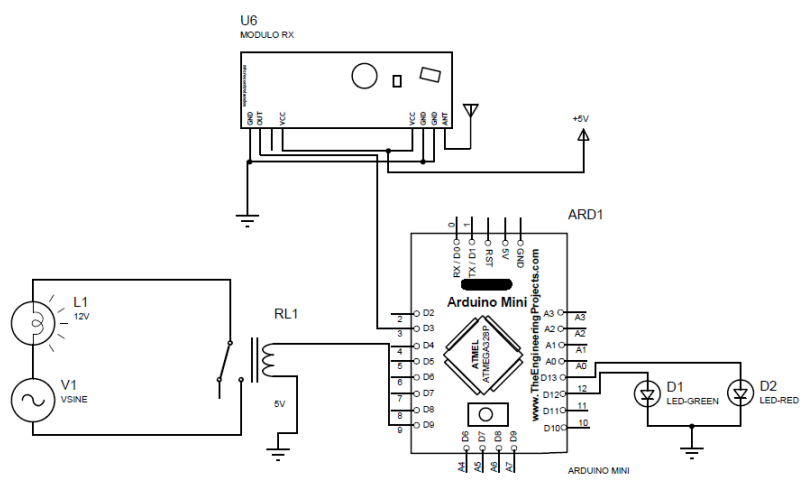

Fig. 4. Disconnection circuit

\section{SOFTWARE DESIGN}

In this disconnection system, both transmitter and disconnection devices are controlled by Arduino Pro Mini. This microcontroller has its own software application known as Arduino IDE that can be installed in Windows operating system. Arduino IDE is available freely and can be downloaded from the Arduino website.

Fig. 5. shows the transmitter flow chart. The process starts with the user key-in the ID number of the respective connection 
device. The function of key B in keypad for the wrong ID and key A on keypad to conform whether the entered ID is correct. If. There are two push buttons used for sending instruction to disconnect or reconnect the electric supply.

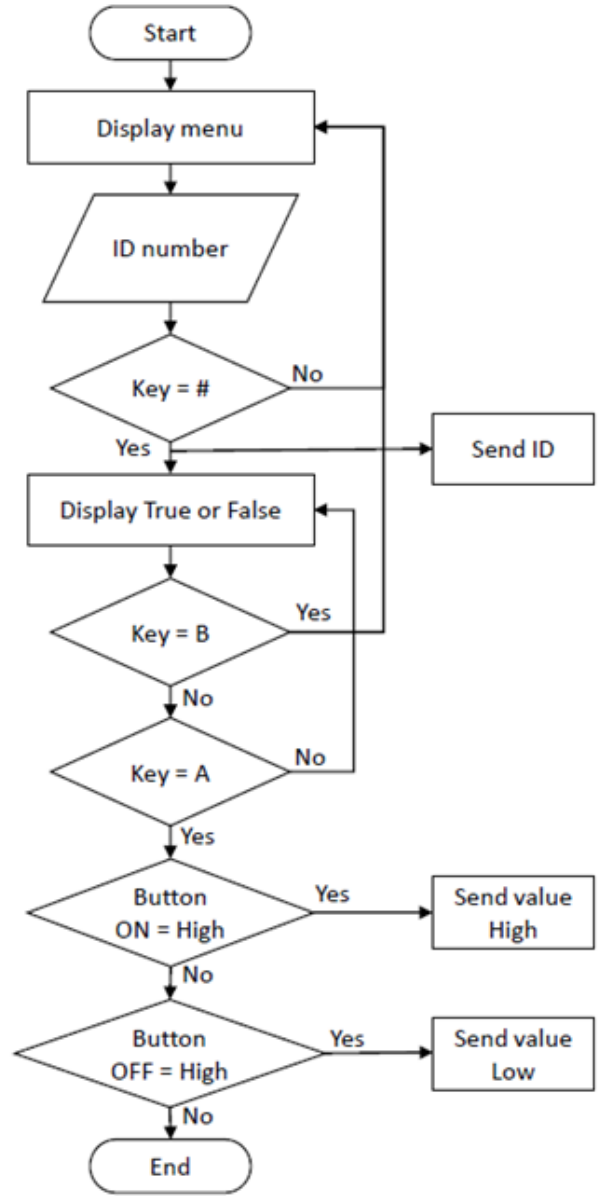

Fig.5. Transmitter Device Flow Chart

Fig. 6 shows the disconnection device flow chart. If the transmitter device sends the correct ID number, LED continuously lights ON. If ID number is incorrect, the LED blinks for 3 seconds and reverts back to standby mode. The next stage when the correct ID number is entered, the disconnection device waits for instruction to cut OFF or reconnect the supply.

\section{EXPERIMENT RESULT}

An Arduino based prototype is developed to test the functionality of hardware and software of the disconnection system to establish its performance expectation. This system was tested in one of the Faculty of Electrical Engineering laboratory (Universiti Teknologi MARA). This experiment was conducted to test the coding as well as the hardware to work as expected. In a normal condition, the incandescent bulb continuously lights up. Fig. 7 shows the set up for the test lamp $100 \mathrm{~W}$ as resistance load light up.

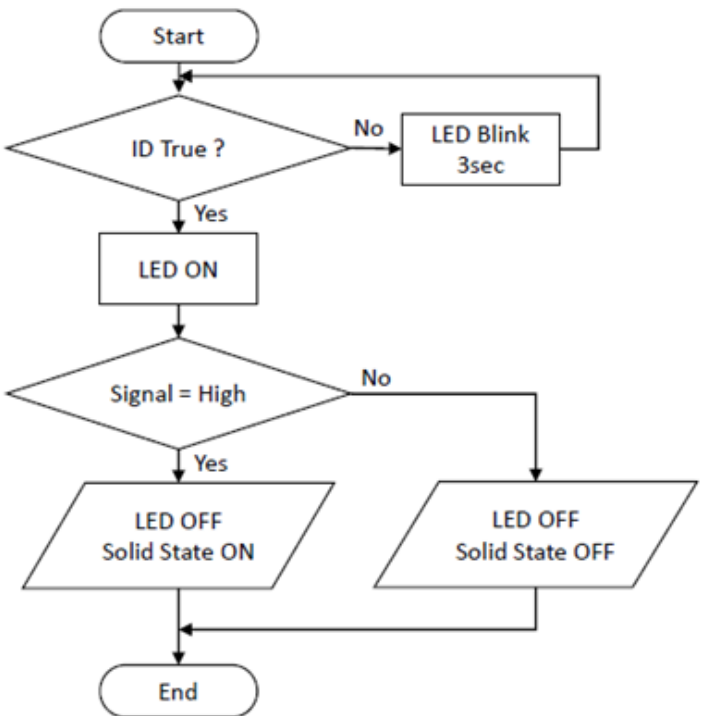

Fig. 6. . Disconnection Device Flow Chart

Fig. 8 shows what has happened after sending instructions to disconnection device which is connected to the energy meter. The control signal will send high signal to activate or turn ON the solid state relay to disconnect the load. Fig.9 shows the normal condition supply waveform with channel 1 (yellow) connected to an incoming supply before the fuse supply voltage $236 \mathrm{~V}$ frequency $49.9 \mathrm{~Hz}$. Channel 2 (blue) is connected to the load and channel 3 (magenta) connected to the Solid-State Relay control signal. The control signal is always high during normal supply.

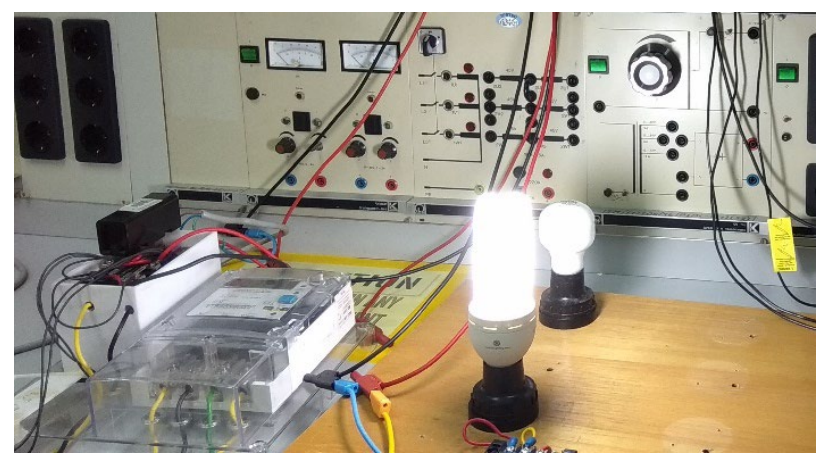

Fig. 7. Normal Load Condition

Fig. 10 shows when the normal condition to cut OFF energy meter control signal from $\mathrm{HIGH}$ to LOW in channel 3. $\mathrm{CH} 1$ (Yellow) shows that a constant $238 \mathrm{~V}$ incoming supply with a frequency of $50.25 \mathrm{~Hz}$. When the instruction signal command to CUT OFF in signal $\mathrm{CH} 3$ (magenta) HIGH to LOW on zero crossings on $\mathrm{CH} 1$, it will detect this to CUT OFF the load.

Fig. 11 shows the CUT OFF supply to Switch ON the supply to Load. At this stage, the load supply $\mathrm{CH} 2$ (Blue) and control signal CH3 (Magenta) is LOW. The instruction command sends the High to control signal. The most prominent time for control signal $\mathrm{CH} 3$ is during the pick signal of incoming supply $\mathrm{CH} 1$. The Solid-state relay will start to operate during the incoming supply signal in zero crossings or zero cycles of signal. 


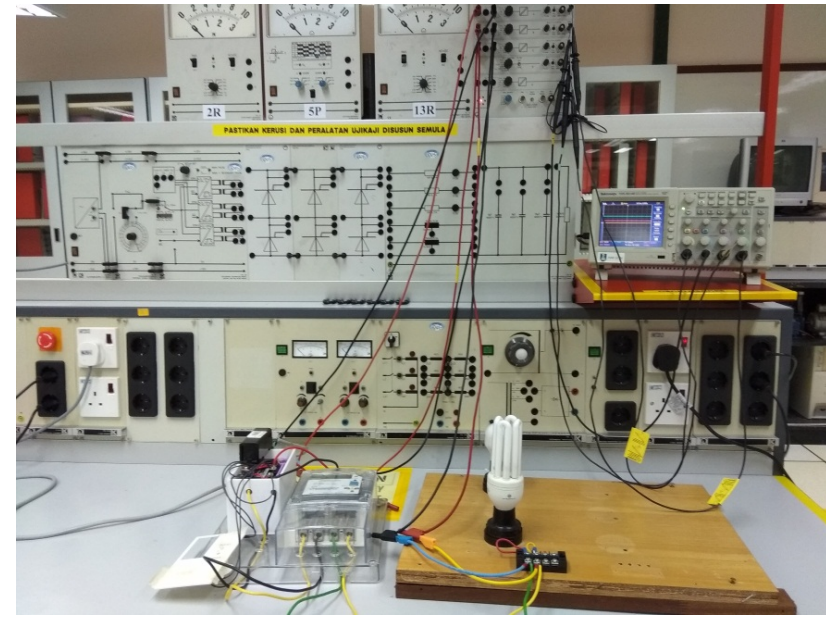

Fig. 8. Disconnection The Load

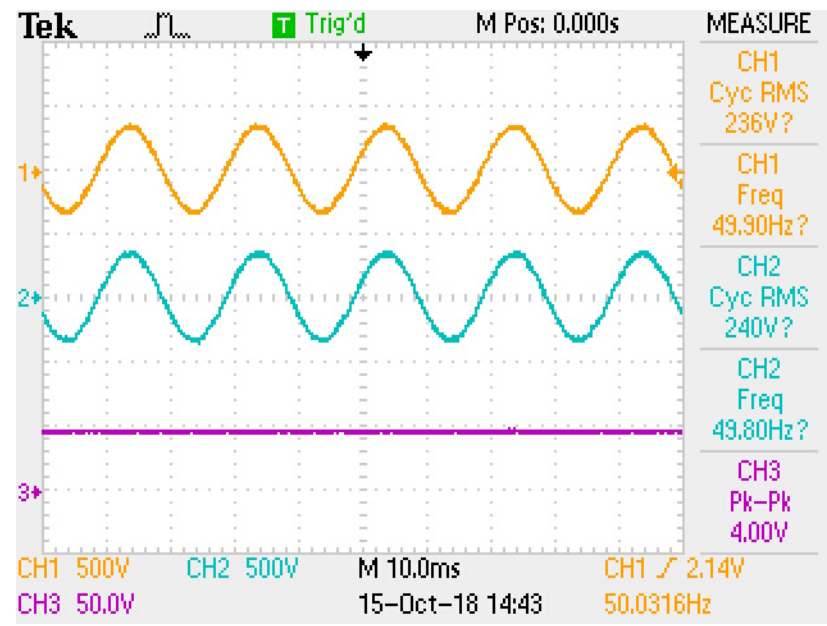

Fig. 9. Load Signal During Normal Condition waveform

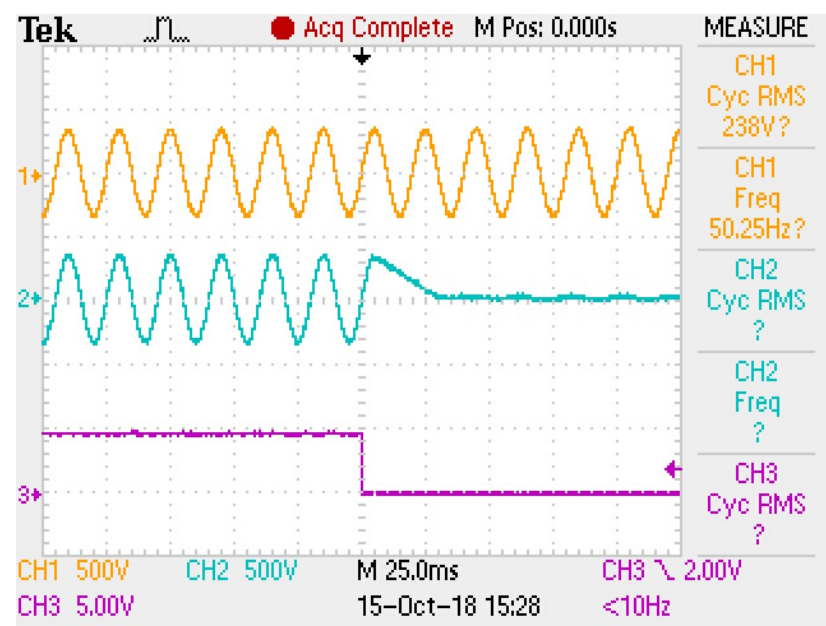

Fig. 10. Wafeform during Disconnection Proses

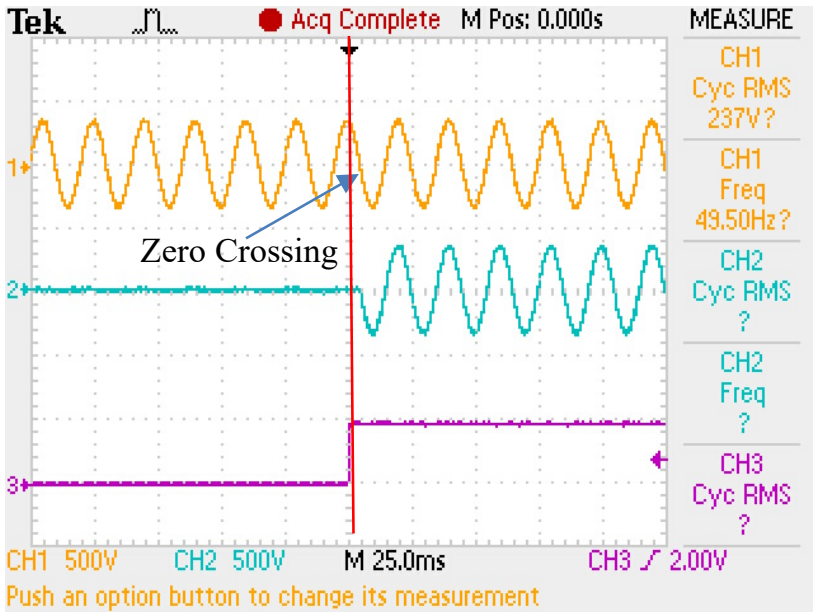

Fig 11 waveform during reconnection Process

The experiment experiment was conducted indoors at an open space in the laboratory for investigating the range distance target of 10 meters from the switch ON/OFF device. Open space means that the panel meter is not covered by a box. Fig. 12 shows the floor plans of the Dream Factory Laboratory. The arrow indicates the direction of the experiment that was performed. Two experiments were conducted, namely direct test and door blocking test.

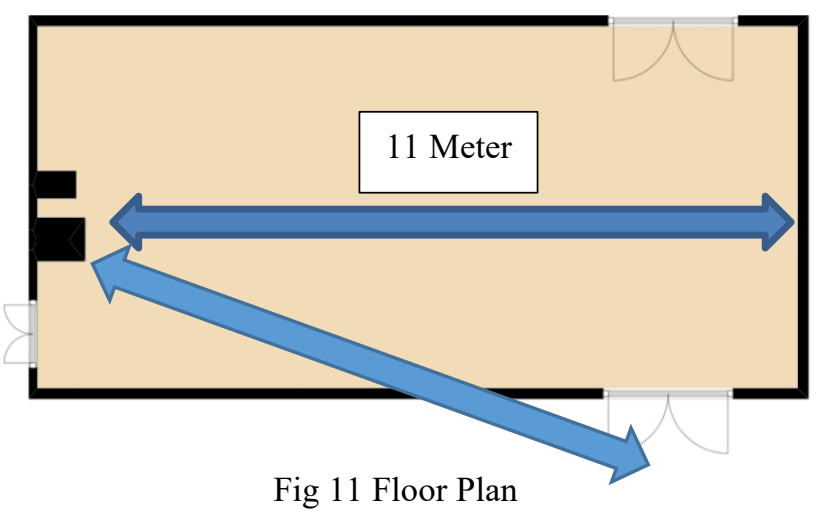

Fig 12 shows the maximum range of the test to Cut OFF the device. There were two different energy meter heights which are $45 \mathrm{~cm}$ and $214 \mathrm{~cm}$ from the floor. The maximum distance measured was 11 meters from the Switch ON/OFF device. The experiment distance measured from 2 meter to 11 meters from the switch ON/OFF device. The 2 Switch ON/OFF devices were successfully CUT OFF from the load. The distance range was measured using a measuring tape. Fig. 13 shows the maximum range to switch $\mathrm{ON}$ the load. Both the devices were successfully switch ON one after another. 


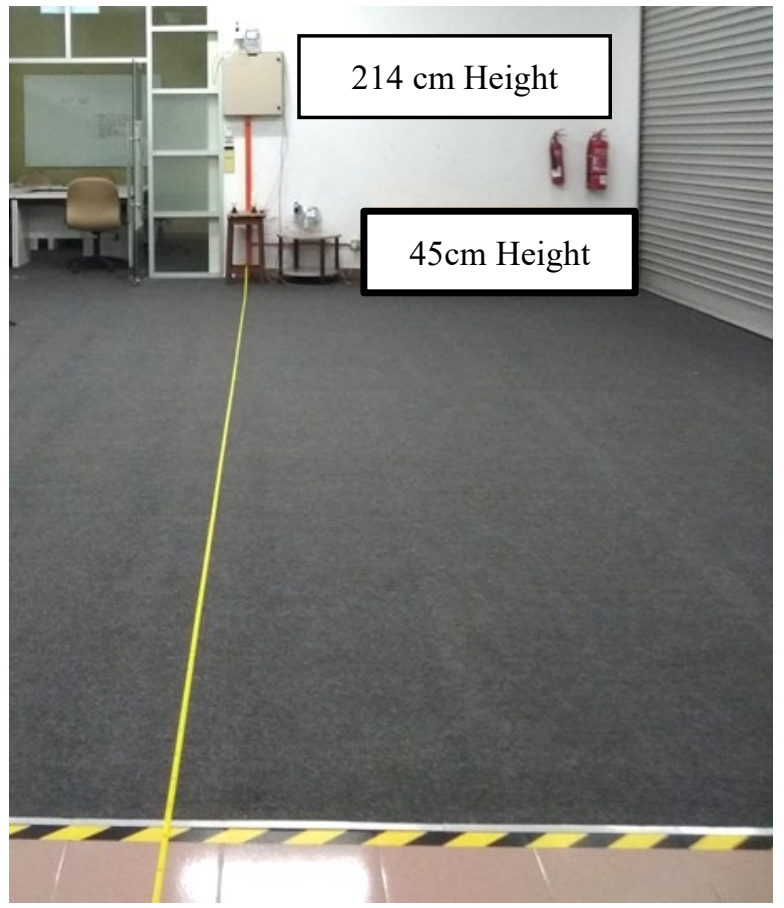

Fig. 12 Maximum Range to CUT OFF Load

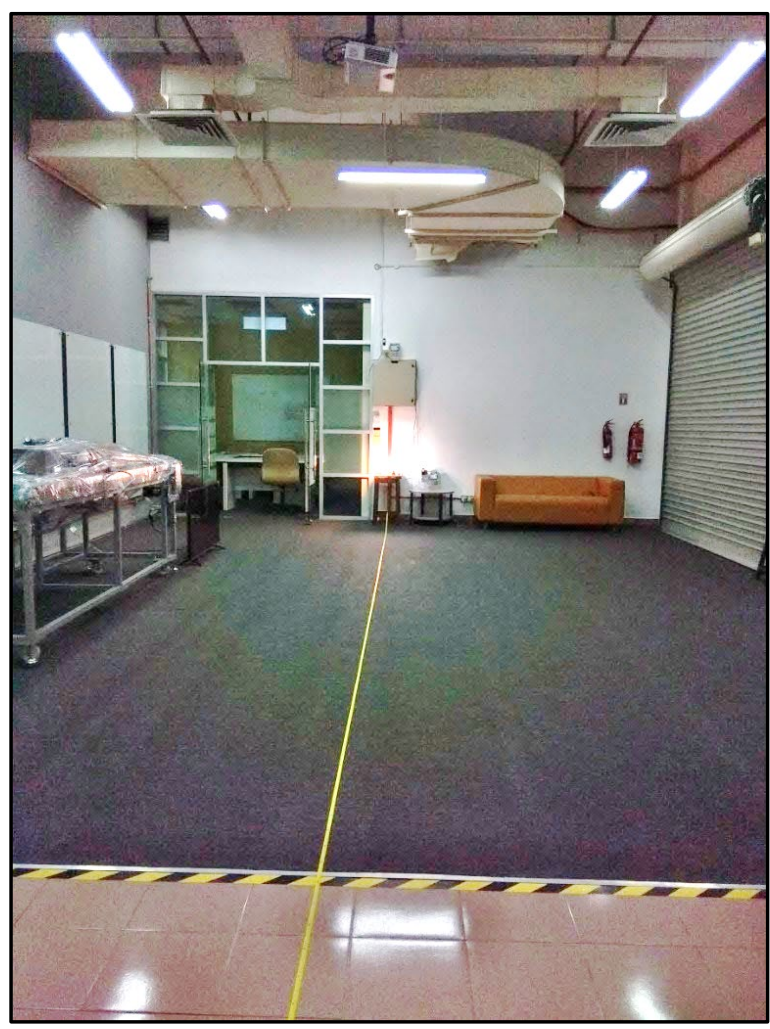

Fig 13 Maximum Range to Switch ON Load

Table 1 shows the results for the open space experiment indoor environment. The experiment started at a distance of 2 meters and increased every 2 meters to the maximum distance 11 meters.
TABLE 1 Result For DISTANCE TESTING

\begin{tabular}{|c|c|c|c|}
\hline $\begin{array}{l}\text { DISTANCE } \\
\text { (METER) }\end{array}$ & $\begin{array}{c}\text { ENERGY } \\
\text { METER } \\
\text { HEIGHT } \\
(\mathrm{CM}) \\
\end{array}$ & $\begin{array}{c}\text { RECEIVER } \\
\text { SYSTEM } \\
\text { ACTION } \\
\text { LOAD } \\
\end{array}$ & RESULT \\
\hline \multirow{4}{*}{2} & \multirow{2}{*}{214} & CUT OFF & \multirow{2}{*}{ SUCCESS } \\
\hline & & SWITCH ON & \\
\hline & \multirow{2}{*}{45} & CUT OFF & \multirow{2}{*}{ SUCCESS } \\
\hline & & SWITCH ON & \\
\hline \multirow{4}{*}{4} & \multirow{2}{*}{214} & CUT OFF & \multirow{2}{*}{ SUCCESS } \\
\hline & & SWITCH ON & \\
\hline & \multirow{2}{*}{45} & CUT OFF & \multirow{2}{*}{ SUCCESS } \\
\hline & & SWITCH ON & \\
\hline \multirow{4}{*}{6} & \multirow{2}{*}{214} & CUT OFF & \multirow{2}{*}{ SUCCESS } \\
\hline & & SWITCH ON & \\
\hline & \multirow{2}{*}{45} & CUT OFF & \multirow{2}{*}{ SUCCESS } \\
\hline & & SWITCH ON & \\
\hline \multirow{4}{*}{8} & \multirow{2}{*}{214} & CUT OFF & \multirow{2}{*}{ SUCCESS } \\
\hline & & SWITCH ON & \\
\hline & \multirow{2}{*}{45} & CUT OFF & \multirow{2}{*}{ SUCCESS } \\
\hline & & SWITCH ON & \\
\hline \multirow{4}{*}{10} & \multirow{2}{*}{214} & CUT OFF & \multirow{2}{*}{ SUCCESS } \\
\hline & & SWITCH ON & \\
\hline & \multirow{2}{*}{45} & CUT OFF & \multirow{2}{*}{ SUCCESS } \\
\hline & & SWITCH ON & \\
\hline \multirow{4}{*}{11} & \multirow{2}{*}{214} & CUT OFF & \multirow{2}{*}{ SUCCESS } \\
\hline & & SWITCH ON & \\
\hline & \multirow{2}{*}{45} & CUT OFF & \multirow{2}{*}{ SUCCESS } \\
\hline & & SWITCH ON & \\
\hline
\end{tabular}

Fig.14 shows the experiment with the door closed blocking with a wall. The position of the energy meter is the same as the previous experiment as shown in Fig 12. Table 2 shows the results for the door blocking by a closed door. The distance measured was 12.08 meter from the energy meter.

\section{CONCLUSION}

In this paper, a disconnection system which take an advantage of TNB to cutting power supply without taking out of the fuse. The RF signal communication use for cutting power incoming supply that can remotely access the fuse to cut OFF and switch ON the load. This system that no have reasons by person in charge to cut OFF supply when they are unable to access the customer premises.

TABLE 2 RESULT FOR DOOR BLOCKING

\begin{tabular}{c|l|c|c}
\hline \multirow{3}{*}{$\begin{array}{l}\text { DISTANCE } \\
\text { (Meter) }\end{array}$} & $\begin{array}{l}\text { ENERGY } \\
\text { METER } \\
\text { HEIGHT (CM) }\end{array}$ & $\begin{array}{l}\text { RECEIVER } \\
\text { SYSTEM }\end{array}$ & \\
& ACTION LOAD & RESULT \\
\hline \multirow{3}{*}{12} & \multirow{2}{*}{246 (wall) } & Cut OFF & \multirow{2}{*}{ Success } \\
\cline { 3 - 3 } & \multirow{2}{*}{789 (wall) } & Switch ON & \\
\cline { 2 - 3 } & & Cut OFF & \multirow{2}{*}{ Success } \\
\cline { 3 - 3 } & & Switch ON & \\
\hline
\end{tabular}




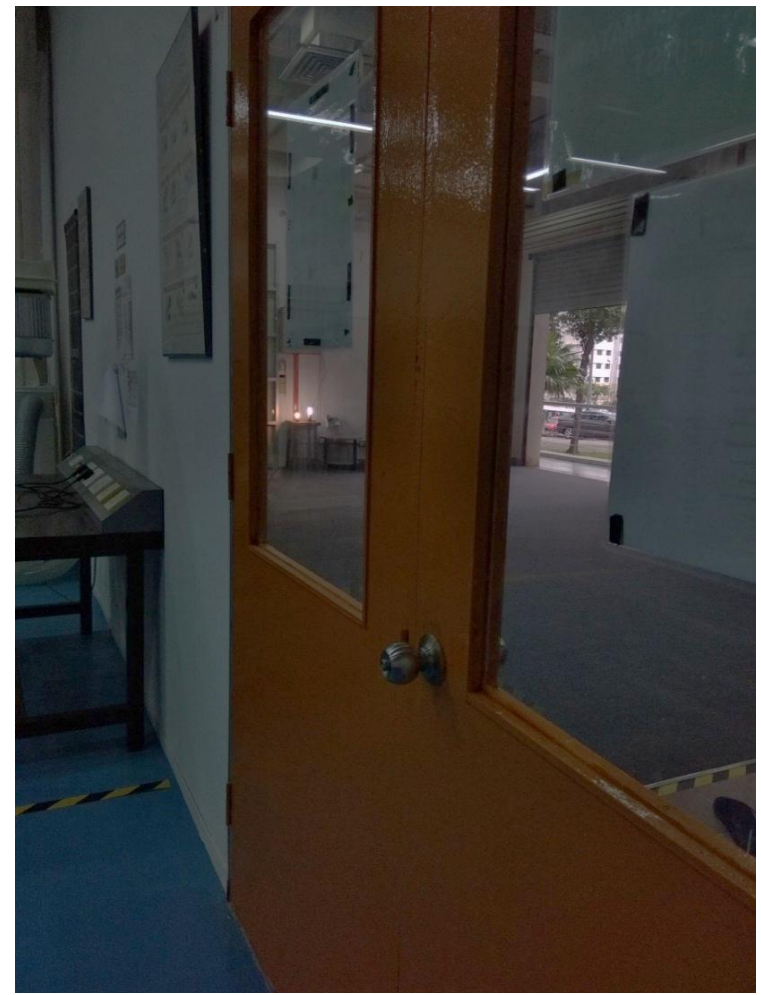

Fig. 14 Door Blocking

\section{REFERENCES}

[1] S Ezhilaeasu, K Riju, K Venkatesh, M Varatharaj. (2015) “ An Enhancment of Prepaid Energy meter Using Smart Card and GSM Module Techniques". IJRE-International Journal of Research in Electronics, ISSN: 2349-252X

[2] Mr.M.V.N.R.P.Kumar, Mr.Ashutosh Kumar, Mr. A.V. Athalekar, Mr. P.G. Desai, Mr. M.P. Nanaware, (2015) “ Electrical Power Line Theft detection" International Journal of Research in Advent Technology, Vol3, No5, E-ISSN: 2321-9637.

[3] H.G. Rodney Tan, C.H.Lee V.H.Mok (2007) "Automatic Power Meter Reading System Using GSM Network" $8^{\text {th }}$ international Power Engineering Conference 2007, pp. 465-469.

[4] www.metering.com/electricity-theft-costs-rm500-million-yearly/(3-122015)

[5] Dae-Man Han and Jae-Hyun Lim, (2010). "Smart Home Energy Management System using IEEE 802.15.4 and ZigBee". IEEE Transactions on Consumer Electronics, 56 (3), 1403-1410.

[6] Suhaila M. Najib, "Microcontroller Based Remote Locator Using Radio Frequency Signal", Faculty of Electrical Engineering, Universiti Teknologi Malaysia, Malaysia, 2010

[7] B.Manisha Sanghamitra, S.Krithiga (2015) Electronics and Communication Engineering, SRM University, India“ Control of electricity thef using ARM7 based prepaid metering system and GSM module" International journal of advanced in Engineering and Science, ISSN (online): 2348-7550

[8] Michael, A. M., Mathew, M., Raghav Nath, Reeja Mathew, \& Rohit Koshy Roy. (2015). Department of Electrical and Electronic Engineering AmalJyothi College of Engineering Kanjirapally, Kottayam, Kerala. "A Smart Prepaid Anti-theft Energy meter". International Journal of Engineering Research in Electrical and ElectronicsEngineering (IJEREEE), 1 (2).

[9] Sai Kiran Ellenki, Srikanth Reddy G, \& Srikanth Ch. (2014). "An Advanced Smart Energy Metering System for Developing Countries". International Journal Of Scientific Research And Education, 2 (1), 242258, ISSN (e): 2321-7545.

[10] G.Vani,V.Usha Reddy. (2015). "Application of Smart Energy Meter in Indian Energy Context". IOSR Journal of Electrical and Electronics Engineering (IOSR-JEEE), 10 (3), 7 - 13, e-ISSN: 2278-1676, p-ISSN: 2320-3331.
[11] Abhinandan Jain, Dilip Kumar, JyotiKedia. (2012). "Design and Development of GSM based Energy Meter". International Journal of Computer Applications, 47 (12). 0975 - 888.

[12] Oyubu A. O., Nwabueze C. A. (2015). "Design and testing of a smart energy metering system based on GSM modem". European Journal of Engineering and Technology. 3 (4), ISSN 2056-5860.

[13] M.Anas, N.Javaid, A.Mahmood, S.M Raza, U.Qasim, Z.A.Khan. (2012) "Minimizing Electricity Theft using Smart Meters in AMI" 7th International Conference on P2P, Parallel, Grid, Cloud and Internet Computing (3PGCIC-2012), Victoria, Canada,

[14] Damian O. Dike, Uchechukwu A. Obiora, Euphemia C. Nwokorie, Blessing C. Dike. "Minimizing Household Electricity Theft in Nigeria Using GSM Based Prepaid Meter". American Journal of Engineering Research (AJER) e-ISSN : 2320-0847 p-ISSN : 2320-0936, 4 (1), 59-69.

[15] SapnaGanurkar, PraveshGour. (2014). "Prepaid Energy Meter for Billing System Using Microcontroller and Recharge Card". International Journal Of Core Engineering \&Management(IJCEM), 1 (1).

[16] Jubi.K, Mareena John Department of Instrumentation and Control Engineering PSG College of Technology Peelamedu, Coimbatore, "India. Prepaid Energy Meter with GSM Technology". American International Journal of Research in Science, Technology, Engineering \& Mathematics.

[17] Abdul Rahman Bin Suratman."Android smart switch for smart home." Degree Thesis, Faculty of Electrical Engineering, Universiti Teknologi Malaysia, Malaysia, 2014

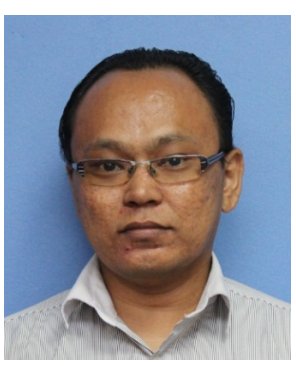

Samshul Munir Muhamad graduated with a B.Eng in Electrical in Power Engineering Universiti Teknologi MARA (UiTM). Currently, he a master student at faculty of Electrical Engineering. He is taking Msc.Eng.Sc in Power Electronics.

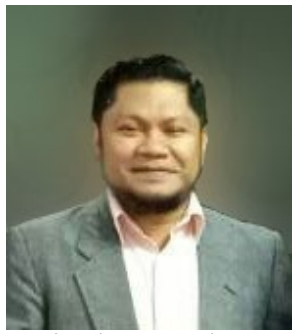

Dr Nawawi is an Associate Professor at the Faculty of Electrical Engineering (FKE), UiTM. He received his first class degree in Electrical Engineering from UiTM in 2001. He pursued his Master's degree in Power Electronics and Drives at The University of Birmingham and The University of Nottingham and successfully completed the doctoral degree in Electrical, Electronic \& Computer Engineering in 2008 from The University of Birmingham, UK. He is also a member to IEEE Professional association since 2003 and currently involved actively in research works pertaining to Power Electronic High-Frequency Converter. 